UCRL-101103

PREPLENT

\title{
Microwave Tokamak Experiment (MTX) Ohmic Heating System
}

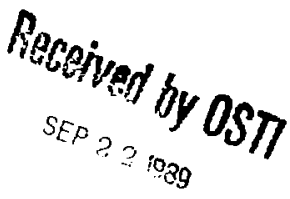

\author{
M. C. Jackson
}

This paper was prepared for submittal to the IEEE 13th Symposium on Fusion Engineering Knoxville, Tennessee

October 2-6, 1989

September 13, 1989

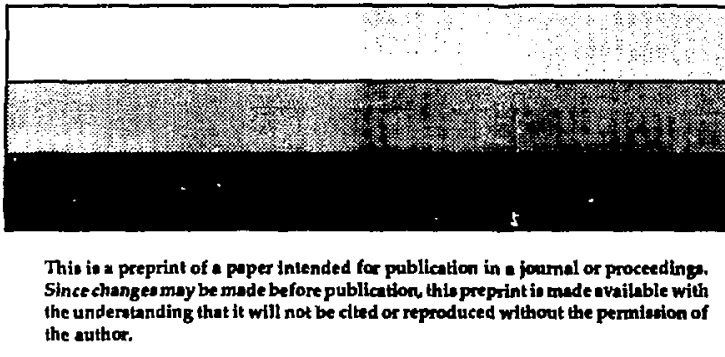

\section{DISCLAIMER}

This report was prepared as an acoount of work sponsored by an agency of the United States Government. Neither the Unitod States Government nor any egency thereof, nor any of their employees, makes any warranty, express or imptied, of assumes any legal liability or tesponsibility for the accuracy, completeness, or usefulness of any information, apparatus, prnduct, of process disclosed, or represents that its use would not infringe privately owned rights. Reference herein to any specilic commercial product, prooess, or service by trade name, trademerk, manufacturer, or otherwise does sot necessarily constitute or imply its endorsement, recommanufacturer, of othing by the United State Government or any agency thercor. The views and opinions of authors expressed berein do not necessarity state or reflecl those of the United Stoter Government of any agency thereof. 


\author{
M. C. Jackson \\ Lawrence Livermore National Laboratory \\ P.O. Box 5511, L-636 \\ Livermore, CA 94551
}

DE89 017892

\section{Abstract}

The ohmic heating system for the Microwave Tokamak Experiment (MTX) at Lawrence Livermore National Laboratory (LLNL) provides both the voltage for the initial breakdown phase and the energy to drive the plasma current to a value of $400 \mathrm{kA}$ or greater. Providing this voltage and flux swing requires a one turn loop voltage of about 25 volis ( $11 \mathrm{kV}$ across the coil) and a magnetic Nux swing of 2 volt-seconds. This voltage and flux swing are accomplished by charging the ohmic heating coils to $20 \mathrm{kA}$, at which point the current is commutated off into a resistor generating the $11 \mathrm{kV}$ across the ooil. When the current passes through zero, another power supply drives the current in the opposite polarity to $20 \mathrm{kA}$, thus conipleting the full 2 voltsecond fux swing.

This paper describes the design features and performance of the ohmic heating circuit, with emphasls on the commutation circuit. In addition, the paper describes the use of the ohmic heating system for discharge cleaning and the changeover procedure.

\section{Introduction}

The Microwave Tokamak Experiment (MTX) at Lawrence Livermore National Laboratory (LLNL) is dedicated to the study of electron-cyclotron heating (ECH) in plasma discharges. The main tokamak for this experiment was previously used quite successfully at the Massachuselts Institute of Technology (MIT), where it was called ALCATOR-C. The tokamak from MIT and the vast majority of the other equipment for the experiment was transporled to LLNL in April 1987. T:- power supplies and the commutation resistor were the only parts of the ohmic heating system that were received from MIT, with MIT retaining its remaining equipment for use in their new C-Mod machine. All of the equipment was in place at LLNL by November 1988, at which time the system was successfully chesked out. 'This paper, then, describes the ohmic heating $(\mathrm{OH})$ system used to initiate and maintain the plasmas for the $\mathrm{ECH}$ heating experiments planned at LLNL.

The ohmic heating coils form an air core transformer with the MTX plasma. The plasma is initiated by rapidly changing the current low in the colls to produce a high ionizing electric field. This field strips the electrons from the molecules and thus generales a plasma. The changing current (dl/dT) in the ohmic heating coils drives a current in the plasma by transformer action, thereby driving and helping to sustain the plasma. This current in turn provides $I^{2} R$ (ohmic) heating for the plasma because of the plasma resistance.

The high peak voltage and power required to initlate the plasma discharge is oblained by using the ohmic heating coil as an inductive energy storage element also. The coil is precharged with the prescribed curtent (up to $20 \mathrm{kA}$ ) and commutated into a resistor to obtain the necessary breakdown voltage (11 kV). After breakdown, the resistance is decreased, thus reducing the plasma buildup rate until the current is driven almost to zero. At that point, another supply drives the current in the negative current direction, thus increasing the total flux swing and associated plasma duration.

\section{Ohmis Heating Cincuis}

A simplified diagram of the ohmic heating circuit is shown in Figure 1. The typlcal operating cycle-consisting of seven phases-is described below and illustrated in Figure 2.

1. Coil Precharge - Circuit breakers $C B 1$ and $C B 2$ are closed and power supply $\mathrm{OH} l$ is turned on. The current is increased to the predetermined value and flat-topped. Most of the current goes through CB1 instead of through $C B 2$ because of the added reststance $R 1$ in the CB2 current path.

2 Current Transfer-Circuit breaker CB1 opens. The opening draws an arc in CB1 that increases the resistance in this current path. The resistance increases to the point that it is significantly larger than R1, at which point the current transfers to CB2 and the are elears in CB1.

3. Counterpulse-Capacitor bank $\mathrm{Cl}$ is precharged and switches $\mathbf{S 1}$ and $\mathbf{S 2}$ opened prior to coil precharge. Circuit breaker CB2 is opened, drawing an arc. Switch $\mathrm{S3}$ is elosed, dumping the capacitor bank $\mathrm{C} 1$ through CB2. The current from $\mathrm{Cl}$ hlows in the opposite direction from isit original precharge current. The sum of the two currents results in a net zero current in CB2, allowing the circuit breaker to clear.

4. Breakdown-The current previously flowing in CB2 now transfers to the current path containing resistor R3. Resistor R3 is adjusted such tha! the current flowing through the resistor produces $11 \mathrm{kV}$ across the $\mathrm{OH}$ coils, causing breakdown in the vacuum ressel and thus initiating the plasma.

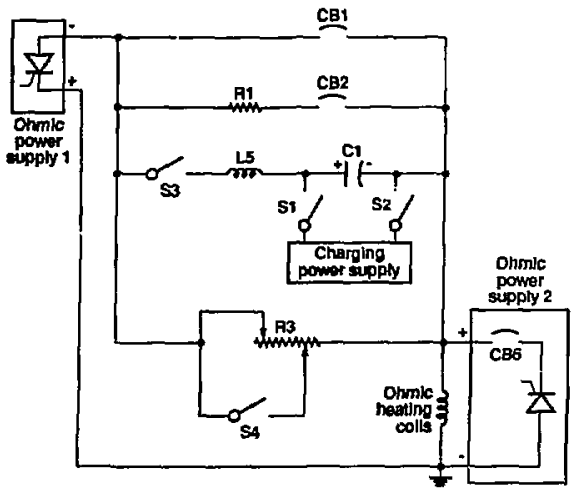

Figure 1. Ohmic heating circult showing the power supplies, colls, and a simpliffed schematic of the commutation circuifing.

- Work performed under the auspices of th: U.S. Department of Energy by the Lawrence Livermore National Laboratory under contract number $W$-7405-Eng-48. 


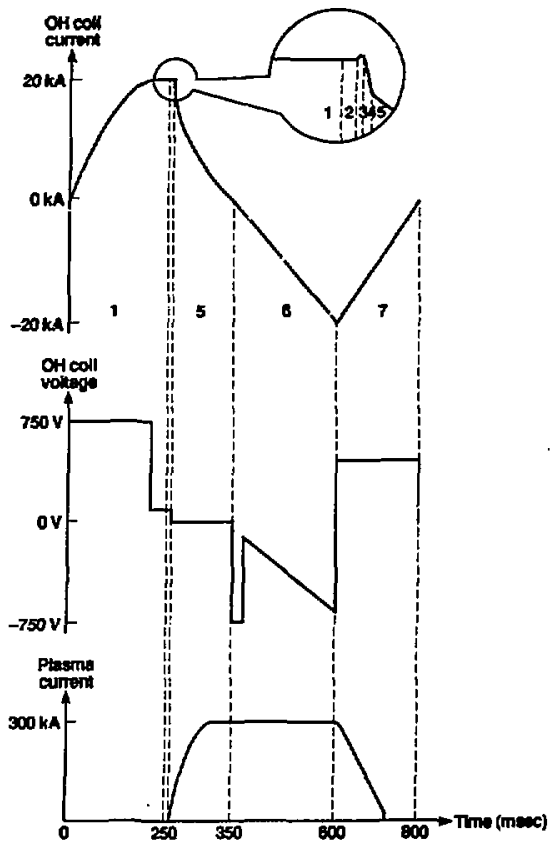

Figure 2. Waveforms of $\mathrm{OH}$ coil current and voltage, and plasma current during a typical seven-phace operating cycle.

5. Crowbar-After breakdown, switch $S 4$ is closed, shorting out part of resistor R3 and changing the decay time constant of the current rampdown. This change allows the operations personnel to control the $\mathrm{dl} / \mathrm{dT}$, which control in tum determines the buildup and drive of plasma current.

6. Current Drive-When the $O H$ current reaches zero, circuit breaker CB6 closes. OH2 power supply then turns on and maintains the same dl/dT, continuing the plasma current untll the supply reaches maximum current.

7. Rampdown-After the current in OH2 power supply has reached its maximum, it is inverted, forcing the current out of the coll. This inversion changes the stgn of the dI/dT, causing the plasma current to be forced to zero.

\section{Implementation}

The actual implementation was not quite as simple as the simplified circult diagram and explanation of operation might indicate. In order to bulld the system quickly and as inexpensively as possible, much of the equipment used was obtalned from previous experiments at LLNL or from various other laboratories. The equipment was then reconfigured to create the ohmic heating system thown in the actual schematc in Figure 3 and the device parameters listed in Table 1. The specific sizing of each plece of equipment and the configuration shown might not be the optimum schlevable had the equipment been specifically designed for this application. The system as a whole, however, does function quite well and has operated

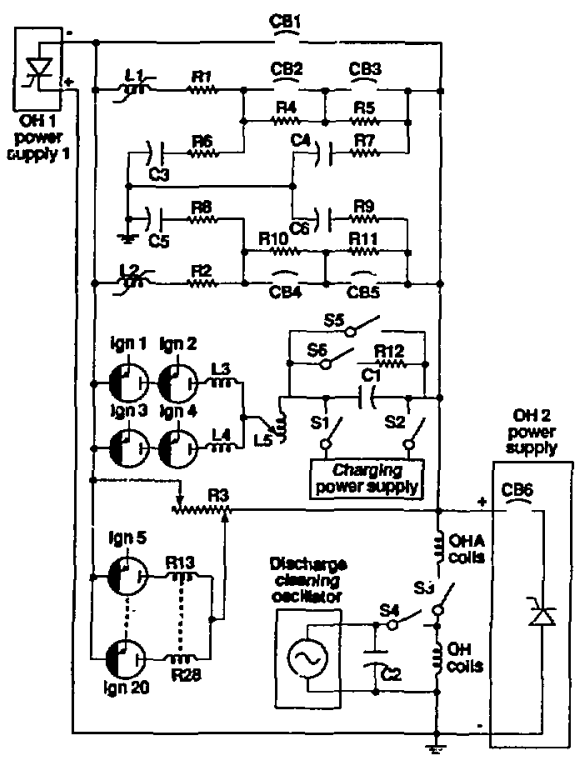

Figure 3. Ohmic heiting system overall schematic, including discharge cleaning equipment.

through many thousands of operational cycles with very few problems.

Circuit breaker CB1 is necessary to keep down the heating In the contact surfaces of vacuum breakers CB2 through CB5. This breaker is a standard 2010 amp, 750 MVA, 3-phase, air magnette circuit breaker. All $\mathcal{Y}$-phase stabs for the line have been shorted together, as have all 3-phase stabs for the load. When the breaker is opened under load, the DC arc will not extinguish because the current never has a current zero. The current naturally commutates to the alternate circuit because of the increased arc Jesistance in CB1. All the arcing occurs around the areing contacts and the bottom of the arc chute. The magnetic blowout colls in the arc chutes do not pull a DC arc into the chutes as they would an AC arc. For this reason, and because of the many operations seen daily, the arcing contacts of the breaker must be maintained regularly. The standard renewal parts for the breaker are very expensive, and because of the way they are packaged for sale, the buyer pays for much more than he actually needs. Because of this, we inspect the contacts often and monitor the wear so that no base material is allowed to wear away and only contact erosion occurs. When a contact needs to be replaced, the contact material is milled off of the base material and the new contact material is furnace brazed into place. In addition, since the breaker only sees current for 's ss than one second, the contact material does not have to be the high-conductivity material (70\% tungsten, 30\% silver) supplied by the manufacturer. Therefore, we have replaced this material with a tougher material composed of $90 \%$ tungsten and $10 \%$ copper to reduce contact wear. With this contact material, we can run approximately 2000 full-current operations before replacing arcing contacts.

Circuit breakers CB2 through CB5 are vacuum interrupters. These breakers were originally uged at $\mathbf{G A}$ 
TABLE 1. OHMIC HEATING SYSTEM PARAMETERS

OH1 \& OH2 Power Supply

$25 \mathrm{kA}, 350 \mathrm{~V}$

Charging Power Supply

$20 \mathrm{kV}$

Discharge Cleaning Oscillator

$20 \mathrm{kV}, 200 \mathrm{~A}, 2 \mathrm{kHz}$

Pulse Length $=7 \mathrm{msec}$

Repetition Rale $=\mathbf{2} \mathrm{Hz}$

Mechanical Breaker (CB1)

3 Phase (Tied Together) 750 MVA, $2000 \mathrm{~A}$, $15 \mathrm{kV}$

Vacuum Interrupters

(CB2, CB3, CB4, CBS)

Vacuum Breaker (CB6)

$32 \mathrm{kV}, 20 \mathrm{kA}$

Max Cond Time $=100$ msec

$25 \mathrm{kA}, 15 \mathrm{kV}$

Fast Close

Interrupter Sharing Resistors (R1, R2)

Commutation Resistor (R3)

Grading Resistors

(RA, R5, R10, R11)

Snubber Resistors

(R6, R7, R8, R9)

Crowbar Sharing Resistors

(R13 through R28)

Saturable Reactors

(LI, L2)

Ignitron Cabling inductance (L3, LA)

Commutation Inductor (L5)

Commutation Cap Bank (C1)

Discharge Clean Tank Cap (C2)

Snubber Cap (C3, C4, C5, C6)

Ignitrons (Ign]-Ign20)

OH Coil

OHA Coil

Stainless Steel Tubing

Water Cooled, $8 \mathrm{m \Omega}$

Stainless Steel Plate

Air Cooled

$1 \Omega$ Tapped

$100 \mathrm{k} \Omega$

$10 \Omega$

Stainless Steel Tubing

Water Cooled, $50 \mathrm{~ms}$

ton $\mu \mathrm{H}$ Salurated

$400 \mu \mathrm{H}$ Unsaturated

$0.1 \mu \mathrm{H}$

$17 \mu \mathrm{H}$

Taps at $15 \mu \mathrm{H}, 12 \mu \mathrm{H}, \&$

$9 \mu \mathrm{H}$

$2.5 \mathrm{mF}, 20 \mathrm{kV}$

$2.1 \mu \mathrm{F}, 20 \mathrm{kV}$

$10 \mu f, 20 \mathrm{kV}$

Size $D$

$9.65 \mathrm{mH}$

$2.59 \mathrm{mH}$

Technologies for the E-coil system.? These interrupters have an internally produced axial magnetic field which promotes highcurrent, stable arcs, lower arc voltage, and low contact erosion in DC applications. Each interrupter is designed to interrupt up to $32 \mathrm{kA}$. Two parallel paths were designed to interrupt up to $64 \mathrm{kA}$ to accommodate a future upgrade of the system to $50 \mathrm{kA}$ without having then to modify the system. The manufacturer's specifications state that the Interrupter can carry high currents for a maximum of only 100 milliseconds. The time limitation is siecessary to avoid contact heating and erosion during the subsequent opening operation and is the reason for the mechanical breaker ( $C B 1$ ), as described eariier. Two internupters are connecied in series in each current path to eliminate reignition after current interruption. To date, this configuration contirues to work with no indications of any reignltions. The vacuum interrupters are mounled two to an operating jnechanism. One operating mechanism opens an interrupter from each current path. Thus if one mechanism fails, the other will still open the circull and meet the 100 -millisecond time requirement.
Items LI through [5, Igni through Ign4, C1, C3 through C6, and R4 through R11 are described generally in reference 3 and more specifically in reference 2. A brief description of these elements is given here, however, for completeness.

The swilch that is used to fire the commutation capacitor bank to extinguish the current in the vacuum interrupters is composed of four ignitrons (Ign1 through Ign4). The ignitrons are arranged in two parallel paths of two ignitrons each. The series arrangement serves to reliably hold off $20 \mathrm{kV}$ if the bank is charged to its full voltage. The parallel arrangement ensures that one of the patlis will fire so that the vacuum interrupter will be commutated off and the interrupter will not carry the arc until the current decays to zero. Each of the series strings is capable of handling the current for the length of time necessary to commutate the vacuum intemupter. Once the ignitrons have been fired, the connected inductances ( $L$ 's) and capacitances (C's) determine the time required to commutate the current oft by its characteristic time constant $1 / \sqrt{L C}$. The current builds to its maximum in a quarter of this characteristic time constant. Therefore, the current is interrupted within thls same quarter of a time constant. For this application, this clearing time is approximately $\mathbf{5 0 0}$ microseconds.

The vacuum internipter, during this extinguishing process, is subject to very large $\mathrm{dl} / \mathrm{dT}$ and $\mathrm{dV} / \mathrm{dT}$ excursions, creating the potential for reignition, as mentioned earlier. This system, as discussed, has been designed to alleviate this situation by connecting the interrupters in series. Additionally, saturable reactors (L1 and $\mathrm{L}_{2}$ ) were added. As the current decreases, the reactor comes out of saturation and increases its inductance. This increase in inductance slows down the clearing time constant and reduces the $\mathrm{dl} / \mathrm{dT}$ to a value within acceptable limits. The $\mathrm{dV} / \mathrm{dT}$ is handled by placing capacitors actoss the open vacuum interrupters. These capacitors limit the rate at which the voltage can build after the current is interrupted.

The resistors in the main current portion of the system are all made from stainless steel. The main commutating resistor, R3, is made from 1/2-inch stainless steel plate equipped with air cooling, and resistors R1, R2, and R13 through R28 are tubing with a water cooling path.

The crowbar tap to the commulating resistor R3 is implemented by 16 size-D ignitrons. The resistors R13 through $\mathrm{R} 28$ are used to aid in the current-sharing between each of the ignitrons. $A 5$ in the case of the vacuum interrupters, the ignitrons were slzed to handle the future needs of higher current applications.

\section{Discharge Cleaning}

Discharge cleaning is performed to rid the vacuum vessel of impurities. These impurities are produced by residue from experimental operations or when the vacuum vessel has been opened to air for equipnent installation. During discharge cleaning, the ohmic heating colls are reconfigured and connected to a supply specially designed for this cleaning purpose. Because of this reconfiguration, experiments and discharge cleaning cannot be conducled simultaneously. The switchover is accomplished by manually opening switch $S_{3}$ and closing switch S4. The discharge cleaning supply applies an oscillatory voltage of $20 \mathrm{kV}$ to the ohmic heating coils at a frequency of $2 \mathrm{kHz}$. This, in much the same way as does the main OH supply, generates a $\mathrm{dI} / \mathrm{dT}$ which creates an ionizing electric field to generate a plasma. This system, however, has a plasma current of only $2 \mathrm{kA}$ for 7 milliseconds at a repetition rate of $2 \mathrm{~Hz}$. The oscillator drives a tank circuit composed of the $\mathrm{OH}$ coil and capacito: $\mathrm{C2}$. The lank circuit is tuned to the same frequency as the oscillator, so that a maximum current can be delivered to the coil with a minimum output from the oscillator. A typical discharge cleaning cycle is two hours at the beginning of a workday following a day of rusning experiments or approximately two working days (16 hours) ifter a major varuum break 


\section{Safety}

The vast majority of $\mathrm{OH}$ buswork is run in open air without any enclosure protecting the system or personnel. This lack of enclosure does not cause a safety problem during normal operation because the area is closed and interlocked. Discharge cleaning, however, represents a problem. Typically, discharge cleaning is performed prior to nuning the experiment. This is also the premilum time to do maintenance. Personnel must therefore be able to work around the experiment while discharge cleaning is operational. At such times, personnel safety is accomplished by an enclosure called the "transition box." This box is the termination point for all the poloidal coil leads exiting the tokamak and all power supply leads entering. During discharge cleaning, all the leads to the power supplies are opened and grounded in the transition box. Thus, any coupling between coils in the tokamak will not generate a voltage back in a power supply where people could be injured. The transition box is interlocked so that it cannot be opened without shutting down the system.

The power is applied to the power supplies only during the physics shot cycle. This ensures that the power is positively killed between operational cycles, thus ensuring personnel safety during intershot inspections and adjustments. This removal of power is accomplished by opening the circuit breaker feeding each supply after the operational cycle. Such usage amounts to a very serious duty for a $15 \mathrm{kV}$ class circuit breaker. For this reason, there are two breakers in series feeding each supply, as shown in Figure 4.

The breaker in the main substation is the main protection for the system. This breaker is opened only during long shutdowns, maintenance, or fault conditions. Since the substation breaker $\therefore$ the main source of protection for the system, the operations on this breaker are purposely kept to a minimum. The breakers opened every shot are those located in the switchgear shed. To track and repair the wear and tear on the breakers associated with the high frequency of operations, an aggressive preventive maintenance schedule is followed.

Realistically, some failures must be expected during service; therefore, special breaker failure detection circuitry has been included. If, one second after the switchgear shed breaker is commanded to trip, the voltage detection circuitry still detects a voltage on any phase, a lockout relay is tripped. This relay trips the substation breaker and locks out the switchgear shed breaker, preventing closing until manually reset at the breaker. This ensures that operatinns personnel must inspect the breaker before operating it again.

\section{Discussion}

This paper has described the design and implementation of the ohmic heating system for MTX. This system was installed and checked out in November 1988. Since that time, the system has performed approximately 5000 operations. The commutation portion of the system has operated flawlessly except for the contact wear in the mechanical breaker, as indicated earlier.

The system has had only one major problem so far. After one of the first successful operations, the $\mathrm{OH} 1$ power supply exploded. The power supply was in a standby state after the rampdown phase, and the main toroidal field supplies had just inverted. This inversion caused an increase in system voltage, and this increase caused the MOV's across each thyrlstor to conduct. This overvoltage lasted for a longer time than the MOV's could handle, and thetr failure caused major shorts across the thyristors and the supply's subsequent explosion. (This situation was not an issue at MIT because theic power was supplied by a motor-generator set. By the time this inversion

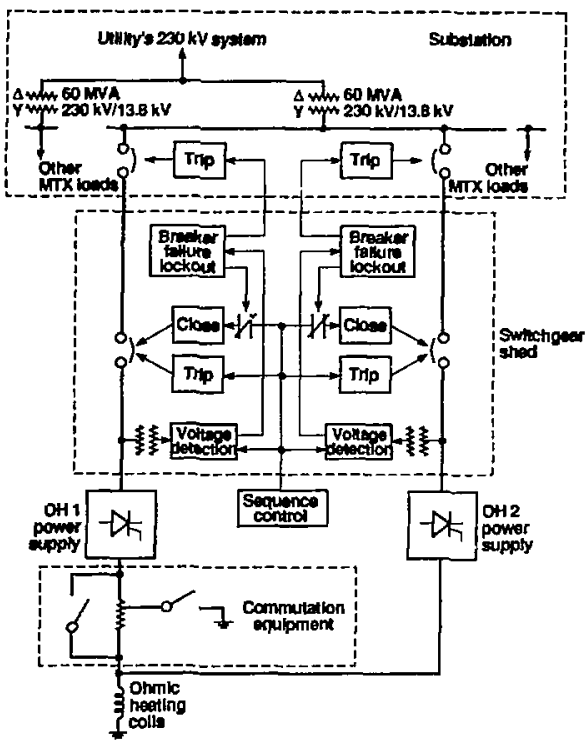

Figure 4. Ohmic heating power system simplifjed one-line diagram and operational safety control schematic.

would happen at MT, the voltage would be down and the inversion would cause no greater increase in the system voltage than the original value.) Subsequently, the power supply has been rebuilt and ts functioning properly.

\section{Acknowlęgments}

The author would like to take this opportunity to thank the electronics technicians who helped assemble, checkout, and operate the system. I would particularly like to thank Scott Hulsey, Robert Guyton, and Joseph Burris for their continuing help and support. Also, thanks to Gloria Glasscox and Toni Nevis for their help in preparing this paper.

\section{References}

1. S. Hibbs, H. Bell, F. Bowman, C. Hitchin, and M. Jackson, "Bringing the Mountain to Mohammed: The Relocation of ALCATOR-C," 12th Symposlum on Fusion Engineerine, 1987, vol. 1, pp. 204-207.

2 R. W. Callis, G. Jackson, I. DeGrassie, P. Peterson, and $E$. Levine, "Function and Operation of the Doublet II E-Coil Vacuum Breaker System," 8th Symposium on Fusion Epelneering, 1979, vol. 3, pp. 1212-1215.

3. A. N. Greenwood and T. H. Lee, "Theory and Application of the Commutation Principle for HVDC Circuit Breakers،" IEEE Transactions on Power Apparatus and Systoms, 1968, Volume PAS-91, pp. 1570-1574. 